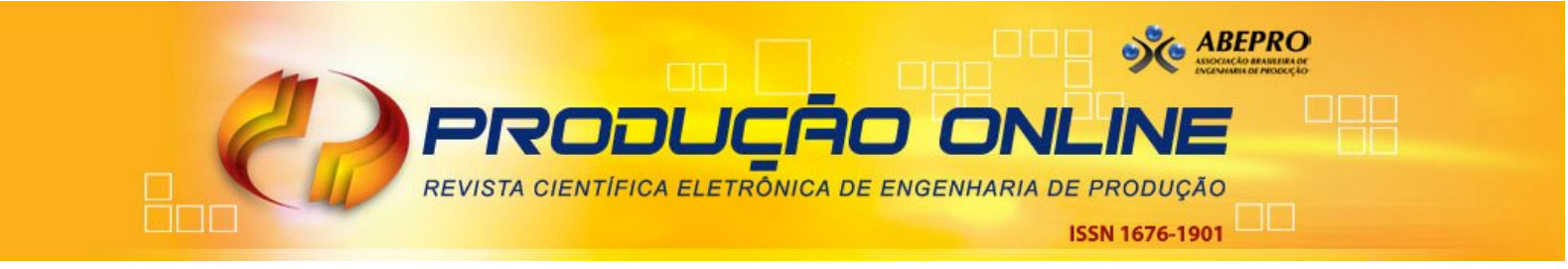

\title{
CONFORTO AMBIENTAL EM SALA DE AULA: ANÁLISE DA PERCEPÇÃO TÉRMICA DOS ESTUDANTES DE DUAS REGIÕES E ESTIMAÇÃO DE ZONAS DE CONFORTO
}

\section{ENVIRONMENTAL COMFORT IN A CLASSROOM: ANALYSIS OF THE THERMAL PERCEPTION OF STUDENTS IN TWO REGIONS AND ESTIMATION OF COMFORT ZONES}

\author{
Ruan Eduardo Carneiro Lucas* E-mail: ruaneduardo94@gmail.com \\ Luiz Bueno da Silva*E-mail: bueno@ct.ufpb.br \\ *Universidade Federal da Paraíba (UFPB), João Pessoa, PB
}

\begin{abstract}
Resumo: Entender a relação térmica que existe entre um indivíduo e um ambiente é importante quando se almeja analisar como as condições existentes influenciam nas atividades. No ambiente escolar não é diferente, e entender o comportamento dos estudantes diante dessas condições tornase fundamental no âmbito educacional. Sendo assim, esse artigo tem como objetivo avaliar o conforto ambiental em dois ambientes de regiões distintas a partir da percepção térmica dos estudantes, e estimar zonas de conforto. Para tal, foi realizado um experimento em um ambiente de ensino na cidade de João Pessoa-PB e outro em São Carlos-SP. A pesquisa foi realizada em três dias, e a temperatura do ar foi manipulada em 20,24 e $28^{\circ} \mathrm{C}$. Em cada dia foram aplicados questionários sobre condições térmicas, visando uma análise comparativa das percepções das amostras das duas cidades. Diante disso, concluiu-se que a amostra de estudantes da região nordeste apresentou uma percepção favorável a temperaturas mais elevadas, diferente da amostra da região sudeste, que apontou uma preferência por temperaturas mais baixas. Por fim, contatou-se que a zona de conforto estimada para a amostra da região nordeste variou entre $22^{\circ} \mathrm{e} 24^{\circ} \mathrm{C}$; enquanto que a zona de conforto da região sudeste foi para uma temperatura próxima de $23^{\circ} \mathrm{C}$.
\end{abstract}

Palavras-chave: Percepção térmica. Conforto térmico. Ambiente de ensino inteligente. Zona de conforto. Sensação térmica.

Abstract: Understanding the thermal relationship between an individual and an environment is important when analyze how the existing conditions provide an efficient performance. Therefore, this paper aims to assess the environmental comfort in two classrooms in different regions, analyzing thermal perception and estimating a comfort zone. The analysis was held at a envirolment in the city of João Pessoa-PB and São Carlos-SP, Brazil. The experiment was conducted in three days, and the air temperature was manipulated 20.24 and $28^{\circ} \mathrm{C}$. On each day questionnaires were about the temperature conditions, thus enabling a comparative analysis of the perceptions of the two cities. Therefore, it is concluded that the sample of students from the northeast region had a favorable thermal perception at higher temperatures, different sample analyzed in the Southeast, which showed a preference for lower temperatures. This result indicates that the adaptability of students in their respective regions influenced this perception.

Keywords: Thermal perception. Thermal comfort. Classroom. Comfort zone. Teaching intelligent environments. Thermal sensation.

\section{INTRODUÇÃO}

Na sociedade contemporânea grande parte da população mundial desempe- 
nha suas atividades em ambientes internos fechados, onde predomina uma má circulação do ar e não propicia contato direto com a radiação solar. Em função disso, as condições ambientais desses lugares podem trazer danos psicológicos e principalmente fisiológicos aos ocupantes. Nesse contexto, Conceição e Lúcio (2011) explicam que a qualidade térmica dos ambientes pode influenciar significativamente na saúde e no conforto humano.

Com os estudantes não é diferente, estes passam a maior parte do seu dia em salas de aula ou em ambientes de ensino inteligente. Esse último é definido como espaços de aprendizagem que dispõem de aparatos tecnológicos, como computadores, data show, entre outros. Esses locais, são exemplos de ambientes fechados no qual as oportunidades de adaptação as condições físicas são limitadas durante o período de aulas (CORGNATI et. al., 2009). Diante disso, torna-se importante analisar as condições existentes, entender as necessidades de adaptação e procurar alternativas na busca por um ambiente termicamente aceitável.

As sociedades atuais passaram a reconhecer que uma educação de qualidade influencia na formação intelectual e eleva o nível cultural, logo, constatouse nos últimos anos um aumento no número de investigações nessa área. Corroborando isso, Almeida e Freitas (2014) indicam que a excelência em educação é um objetivo claro de qualquer sociedade moderna. Nesse contexto, faz-se necessário proporcionar aos estudantes estruturas físicas e condições ambientais de qualidade, que proporcionem um desenvolvimento mais adequado de suas capacidades cognitivas, como memorização, percepção e o raciocínio lógico.

Assim, entender a afinidade das pessoas quanto ao ambiente térmico e avaliá-lo torna-se essencial. A avaliação desses ambientes acontece a partir do conforto térmico, que segundo Coutinho (2009) é um estado de espírito que reflete a satisfação do indivíduo com as condições térmicas do ambiente no qual está inserido. Para o cálculo desse índice, leva-se em consideração variáveis físicas, como temperatura do ar, temperatura radiante média, umidade relativa, entre outras (KATAFYGIOTOU; SERGHIDES, 2014).

Logo, avaliar os parâmetros térmicos do local e compreender a percepção dos ocupantes é de extrema importância quando se deseja oferecer condições térmicas de qualidade. Sendo assim, o objetivo desse estudo é avaliar o conforto 
ambiental de duas salas de aula em regiões distintas, analisar a percepção térmica dos estudantes e estimar uma zona de conforto visando a maximização do desempenho durante a realização das atividades.

\section{JUSTIFICATIVA}

O estudo do conforto térmico é um método de análise ambiental bastante difundido e que fornece informações contundentes na busca pela otimização ambiental. Nesse sentido, vários pesquisadores desenvolveram e desenvolvem estudos nessa área, trazendo assim, contribuições ergonômicas efetivas.

$\mathrm{Na}$ Itália por exemplo, Corgnati et. al. (2009) desenvolveu uma pesquisa em salas de aula na cidade de Turim. A metodologia aplicada consistiu na medição de parâmetros físicos e pessoais para cálculo dos índices PMV e PPD. Realizou-se também a avaliação subjetiva das condições ambientais, ou seja, investigou-se a percepção térmica a partir de questionários para um total de 230 estudantes.

Com relação aos adolescentes e pré-adolescentes as pesquisadoras Katafygiotou e Serghides (2014) realizaram um estudo de caso em uma escola secundária do Chipre. Durante o período de aula os parâmetros climáticos foram registrados minuto a minuto afim de que se pudesse calcular o PMV e o PPD. Simultaneamente com as medições de campo, questionários e entrevistas foram aplicados a fim de estudar o conforto térmico.

Os estudos de conforto térmico não se restringem apenas ao continente europeu. Na República Popular da China, Wang et. al. (2014) realizou um estudo nas salas de aula das universidades em Harbin durante o inverno e a primavera. Através dessa pesquisa, foram analisadas as relações entre adaptação térmica e climas interiores, como também, se a mudança da temperatura interna influenciaria no conforto. No mesmo continente, mais precisamente na Índia, Mishra e Ramgopal (2014) realizaram um estudo em salas de aulas e em um laboratório. Além de medidas objetivas das variáveis ambientais internas, também foram coletadas respostas subjetivas sobre a percepção quanto à sensação térmica, preferência térmica, velocidade do ar e umidade.

Seguindo nessa linha de pesquisa em laboratórios, Hussin et. al. (2013) investigou as condições ambientais e o conforto dos ocupantes do campus de 
engenharia de uma universidade. A metodologia foi a mesma utilizada na Índia, entretanto, os questionários subjetivos basearam-se na escala de sete pontos e foram utilizados para avaliar a sensação térmica dos ocupantes do laboratório.

Por fim, Teli et. al. (2012) realizou um estudo em salas de aulas que não possuíam sistema de refrigeração mecânica no condado de Hampshire, Inglaterra. Diferente das pesquisas citadas anteriormente, não foi aplicado questionários a respeito das condições térmicas, haja vista que a amostra era composta de crianças de 7 a 11 anos. Logo, os autores observaram que os modelos usados na análise do conforto térmico (PMV e PPD) foram limitados na estimação das condições de conforto térmico nas escolas. Considerou-se isso pois os modelos não refletiam precisamente a sensação térmica real das crianças.

Diante desse cenário contata-se a importância e diversidade do estudo do conforto térmico em salas de aula e em ambientes de ensino inteligente. Destaca-se também a importância da análise subjetiva, que está presente na maioria dos trabalhos e reflete a real sensação dos ocupantes. Diante disso, o objetivo de analisar o conforto térmico em dois ambientes no Brasil vai de encontro ao que está sendo estudado no mundo e ainda supre uma lacuna que existe na maioria dos trabalhos, que é a inexistência das temperaturas de conforto. A estimação das temperaturas confortáveis é importante pois leva em consideração a aclimatação dos estudantes com as condições térmicas vivenciadas cotidianamente. Nesse contexto, esse trabalho contribui com a estimação das zonas de conforto para os ambientes localizados em regiões que apresentam condições térmicas e culturais diferentes.

\section{COMPORTAMENTO DO CORPO HUMANO MEDIANTE ALTERAÇÕES TÉRMICAS}

O corpo humano apresenta dois tipos de temperatura na sua interação com o ambiente. Uma temperatura neutra, que é definido por Fanger(1970) como sendo uma condição na qual o indivíduo está em neutralidade térmica, isto é, situação em que não prefira sentir nem mais frio, nem mais calor no ambiente; e um temperatura interna, temperatura comum a todos os indivíduos no valor de $37^{\circ} \mathrm{C}$. 
Os mecanismos termorreguladores são dispositivos que buscam alternativas e criam condições para que a temperatura interna permaneça sempre constante no valor de $37^{\circ}$ (COUTINHO,2009). Ou seja, para qualquer alteração que ocorra, seja aumento ou diminuição da temperatura, o organismo vai buscar alternativas para que temperatura interna esperada seja atingida novamente.

De acordo com Blatteis(1997) o corpo humano possui dois sensores, um de alta temperatura localizado no hipotálamo, e outro de baixa temperatura distribuído por toda a pele. Esses sensores enviam mensagens ao cérebro com uma frequência proporcional as alterações por eles notadas. Os sensores de alta temperatura enviam impulsos ao mecanismo termorregulador e ao córtex quando a temperatura do sangue aumenta. Já os de baixa, enviam impulsos ao hipotálamo e ao córtex quando a temperatura da pele começa a cair. O córtex por sua vez responde com atos conscientes, enquanto que o mecanismo termorregulador controla inconscientemente a temperatura.

Em relação ao córtex os processos que se destacam são: Para temperaturas internas acima de $37^{\circ} \mathrm{C}$ a vasodilatação, que é a expansão dos vasos sanguíneos na busca pela maior vazão do fluxo de calor; e quando a vasodilatação não é suficiente ocorre o processo de sudorese, ou seja, o indivíduo passa a eliminar o calor por evaporação. Para temperaturas internas abaixo de $37^{\circ} \mathrm{C}$ ocorre um processo de vasoconstricção, que é a compressão dos vasos sanguíneos na visando a menor vazão do fluxo.

O mecanismo termorregulador por sua vez age com atos inconscientes. De acordo com Yao et. al.(2009), os ocupantes de um determinado ambiente podem atingir o conforto térmico através de pequenas ações inconscientes, seja adicionar ou retirar roupas, beber água gelada, abrir/fehcar de janelas, ligar / desligar ventiladores, etc. São ações orientadas pelos mecanismos termorreguladores na busca pela temperatura interna adequada. A figura 1 esquematiza o que foi retratado. 
Figura 1 - Funcionamento do corpo mediante alterações na temperatura interna

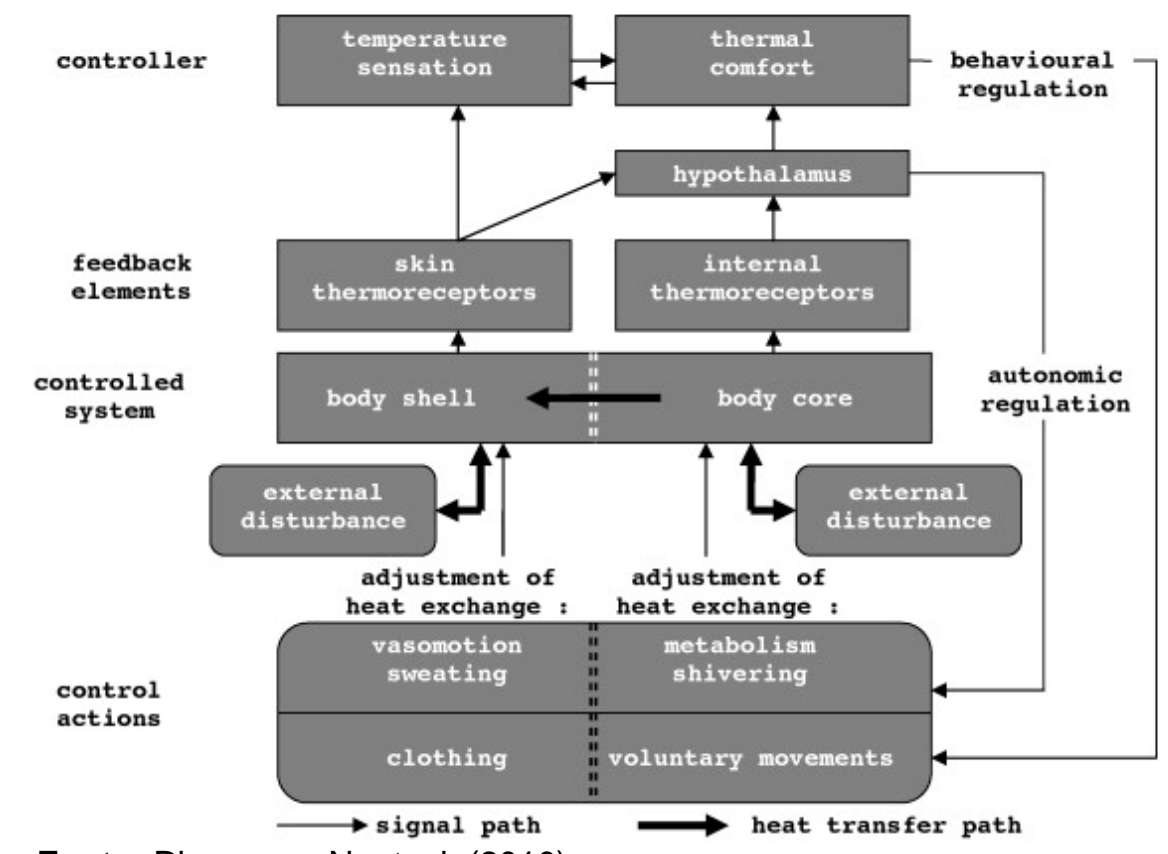

Fonte: Djongyang N. et. al. (2010)

\subsection{Balanço térmico}

O corpo humano desempenha atividades internas e externas que geram calor e ficam acumulado na superfície corporal. Em contrapartida, o corpo dispõe de um conjunto de mecanismos que trabalham na dissipação desta carga térmica. Nesse cenário, o balanço térmico demonstrado pela equação (1) expressa a relação de entrada e saída do fluxo de calor no organismo.

O cálculo do balanço térmico é definido pela ISO 7793 (Equação 1) e leva em consideração alguns parâmetros, como taxa metabólica do corpo na realização da atividade; troca de calor por condução; troca de calor por convecção; troca de calor por radiação; troca por evaporação no trato respiratório; e troca por convecção no trato respiratório. Analisando essa equação infere-se que o corpo estará em equilíbrio quando a taxa de calor absorvida for igual a taxa de calor dissipada.

$$
M-T=C_{r e s}+E_{r e s}+K+C+R+E+S
$$

sendo:

M - Geração da taxa metabólica $\left(\mathrm{w} / \mathrm{m}^{2}\right)$

T- Trabalho mecânico (w/m²)

CRES - Troca por convecção no trato respiratório (w/m²)

ERES - Troca por evaporação no trato respiratório $\left(\mathrm{w} / \mathrm{m}^{2}\right)$

Revista Produção Online. Florianópolis, SC, v.17, n. 3, p. 804-827, 2017. 
K - Troca de calor por condução $\left(\mathrm{w} / \mathrm{m}^{2}\right)$

C - Troca de calor por convecção $\left(w / m^{2}\right)$

$\mathrm{R}$ - Troca de calor por radiação $\left(\mathrm{w} / \mathrm{m}^{2}\right)$

$\mathrm{S}$ - Armazenamento de calor, acumulando-se no corpo $\left(\mathrm{w} / \mathrm{m}^{2}\right)$

\section{CONFORTO TÉRMICO EM AMBIENTES TERMICAMENTE MODERADOS}

O conforto térmico é um estado psicológico onde o indivíduo apresenta contentamento com os parâmetros termoambientais do local onde está inserido. A ASHRAE 55(1992) por sua vez o define como sendo uma condição da mente que expressa satisfação com o ambiente térmico. Com a existência dessa condição, os ocupantes tendem a desempenhar suas atividades de forma mais precisa e eficiente, influenciando beneficamente o seu desempenho.

Estuda-se essa temática para analisar e avaliar as condições necessárias para que o ambiente seja adequado as atividades e ocupações humanas (LAMBERTS; XAVIER, 2002). Considera-se que essa condição é influenciada por variáveis como: Atividade desempenhada; Isolamento térmico das roupas utilizadas; Temperatura do ar; Temperatura radiante média; Velocidade do ar e Umidade do ar.

Ambientes termicamente moderados são ambientes onde existe o conforto térmico, por exemplo, sala de aula, bibliotecas, laboratórios, entre outros. Segundo Coutinho (2009), o conforto térmico necessita de três condições para ocorrer: Neutralidade térmica, que consiste em manter a temperatura neutra do corpo humano constante; taxa de suor liberada pela pele e a temperatura da pele têm que ser compatíveis com a atividade realizada; e por último, o indivíduo não pode estar sendo submetido a nenhum desconforto localizado, ou seja, nenhuma parte do corpo pode estar submetida a uma fonte constante ou intermitente de fluxos térmicos.

Segundo a ISO 7730(2005) a avaliação de ambientes termicamente moderado é realizada a partir de dois índices: O voto médio estimado (PMV), e a percentagem de pessoas insatisfeitas (PPD). Ter Mors et. al. (2011) explica que o cálculo do PMV leva em consideração as propriedades termo fisiológicas dos seres humanos e seu equilíbrio térmico com o meio ambiente. A equação (2) indica o cálculo do voto médio estimado. 


$$
\begin{aligned}
& P M V=\left(0.303 e^{-0.036 M}+0.028\right) x\left[\left(M-W^{\prime}\right)-3.05 X 10^{-3} \cdot\left\{5733-6.99\left(M-W^{\prime}\right)-P a\right\}\right. \\
& -0.42\left\{\left(M-W^{\prime}\right)-58.15\right\}-1.7 X 10^{-5} \cdot m \cdot(5867-P a)-0.0014 . M .\left(34-T_{a}\right) \\
& \left.\left.-3.96 \times 10^{-8} \cdot f_{c l} \cdot\left\{T_{c l}+274\right)^{4}-\left(T_{r}+273\right)^{4}\right\}-f_{c l} \cdot h_{c} \cdot\left(T_{c l}-T_{a}\right)\right]
\end{aligned}
$$

O cálculo leva em consideração parâmetros como: Taxa metabólica gerada pela atividade desempenhada; Isolamento térmico das roupas utilizadas; Temperatura do ar; Temperatura radiante média; Velocidade do ar; e Umidade absoluta do ar. A partir desse índice calcula-se o PPD como mostra a equação (3). Djongyang et. al.(2010) o define como sendo a percentagem de pessoas que estão inclinados a reclamar das condições térmicas propostas.

$$
P P D=100-95 * \exp \left(-0,03353 * P M V^{4}-0,2179 * P M V^{2}\right)
$$

Fanger(1970) indica que um voto médio estimado entre $-0,5<\mathrm{PMV}>0,5$ resultará em um PPD inferior a 10\%. Ou seja, diante da inexistência de um ambiente em que todos os indivíduos estejam satisfeitos com as condições térmicas propostas, o percentual de PPD de 10\% é tido como o ideal. A figura 2 mostra a relação apresentada acima.

Figura 2- Relação entre PMV e PPD

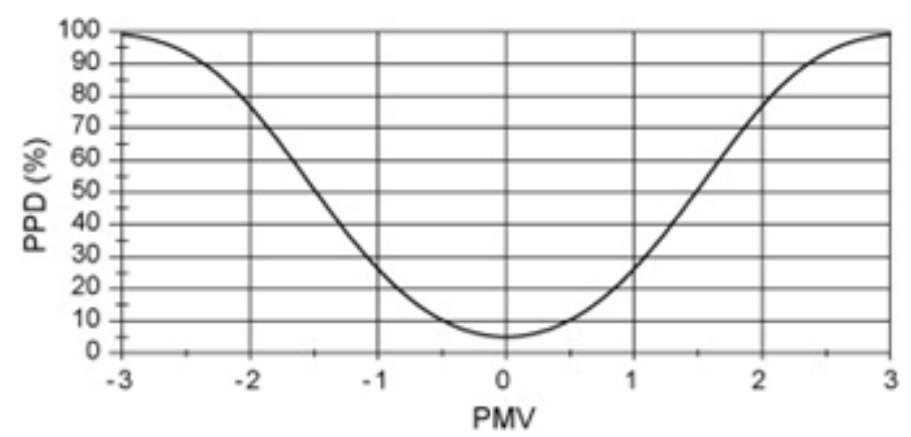

Fonte: Djongyang N. et. al. (2010)

\section{ASPECTOS METODOLÓGICOS}

A pesquisa de caráter experimental foi realizada em dois ambientes situados em regiões distintas do Brasil (Regiões nordeste e sudeste). Nesse estudo foi 
manipulado a temperatura do ar visando identificar a percepção e o conforto térmico dos ocupantes mediante tais alterações.

O tamanho da amostra foi estipulado mediante a equação de Cochran(1977), que está expressa nesse trabalho pela equação 4. Segundo o autor, $N$ é valor total da população; Za é igual a 1,962 para um nível de significação de 5\%; $p$ é frequência esperada (quando não se conhece esse valor adota-se 0,50); q é igual a 1- $p$; $d$ é o erro aceitável ( $d=5,55 \%$, para um nível de significância de $5 \%$ e $p$ igual a $0,50)$.

$$
n=\frac{N \cdot p \cdot q \cdot Z \alpha^{2}}{(N-1) \cdot d^{2}+Z \alpha^{2} \cdot p \cdot q}
$$

\subsection{Instituição investigada na Região Nordeste}

A pesquisa realizada no nordeste brasileiro foi em João Pessoa, estado da Paraíba, Brasil. O clima predominante é o tropical úmido, com temperaturas e umidades relativas altas. O campo de pesquisa foi uma faculdade local, e as coletas ocorreram entre os dias 18 e 27 de agosto de 2014. A sala de aula possuía dimensões 9,8 m x 7,8 m; com duas janelas centrais que impediam a incidência da luz solar; e um ar condicionado localizado no final do ambiente. A sala de aula foi dividida em quatro zonas, duas próximas ao quadro (zonas 1 e 2), uma próxima ao sistema de refrigeração (zona 3), e uma centralizada (zona 4). Foram utilizados 34 computadores, dispostos em 12 bancadas com três computadores cada. A figura 3 ilustra o ambiente analisado.

Fizeram parte da amostra 76 alunos de engenharia (turmas 1,2 e 3), que gozavam de plena saúde. As coletas vinculadas às sensações térmicas foram realizadas em três dias, 18, 20 e 27 de agosto de 2014. A temperatura do ar foi ajustada para 20,24 e $28^{\circ} \mathrm{C}$, respectivamente aos dias anteriores. As demais variáveis físicas como velocidade do ar, temperatura radiante média, e umidade relativa do ar não foram manipuladas, ou seja, fez-se o experimento com as condições reais dessas variáveis. 


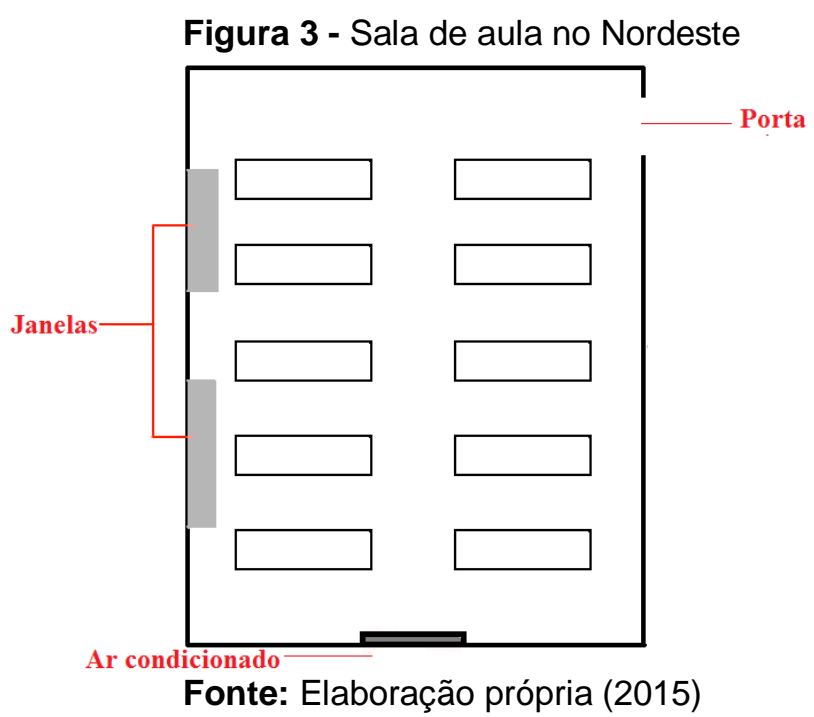

Com os alunos no ambiente e aclimatados com as condições térmicas foi realizada uma avaliação subjetiva, onde questionou-se acerca de informações pessoais, como sexo, idade, peso, roupa utilizada, entre outras. Indagou-se também a respeito da percepção com relação às condições ambientais, mais precisamente a sensação e o conforto térmico.

A avaliação subjetiva do conforto térmico foi baseada em uma escala (Figura 4) que variou de -3 a 3 , e foi classificada em: Muito desconfortável (-3), Levemente desconfortável (-2), Desconfortável (-1); Neutro (0); Confortável (1); Levemente confortável (2) e Muito confortável (3). A avaliação da sensação térmica também utilizou uma escala de sete pontos: Muito frio (-3); Frio (-2); Levemente frio (-1); Neutro; Levemente quente (1); Quente (2); e Muito quente (3). De posse dessas respostas tornou-se possível identificar as tendências perceptivas dessa amostra.

Figura 4 - Escala de sete pontos

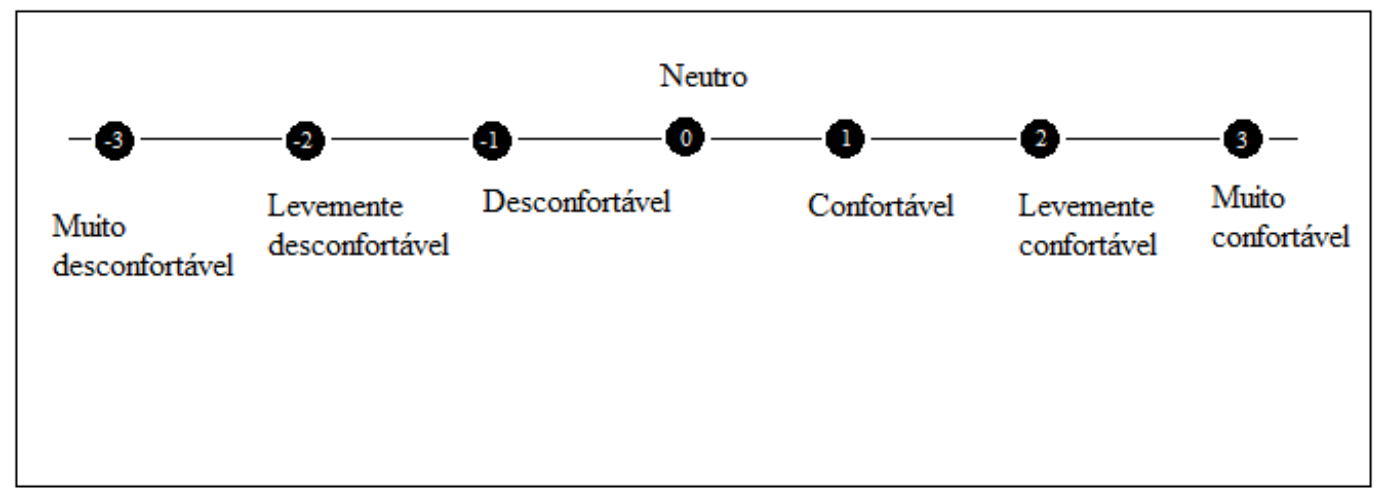

Fonte: Elaboração própria (2015) 
Em paralelo foi realizado uma avaliação objetiva, ou seja, foram mensurados os parâmetros físicos como temperatura do ar, temperatura radiante média, velocidade do ar e umidade relativa, com o intuito de posteriormente calcular os índices PMV e o PPD. As medições foram feitas através de um medidor de estresse térmico localizado no ponto central do ambiente. O equipamento foi ligado 30 minutos antes do início do experimento para que estabilizasse com as condições ambientais existentes, e posteriormente capturasse os parâmetros de minuto a minuto.

De posse das informações experimentais iniciou-se o processo de apreciação. Inicialmente separou-se os dados de acordo com turma e dia de análise. Posteriormente, utilizou-se as técnicas presentes no software estatístico R para uma visualização mais precisa do comportamento dos dados; compreensão do ambiente térmico; identificação da percepção dos estudantes; e compreensão da relação entre percepção térmica e parâmetros físicos existentes.

\subsection{Instituição investigada na Região Sudeste}

O clima predominante na região sudeste é o tropical semiúmido onde a temperatura média anual é de $22^{\circ} \mathrm{C}$. Dentro dessas condições, realizou-se medições em uma sala de aula na cidade de São Carlos- SP. A figura 5 esquematiza o local analisado.

Figura 5 - Sala de aula região sudeste

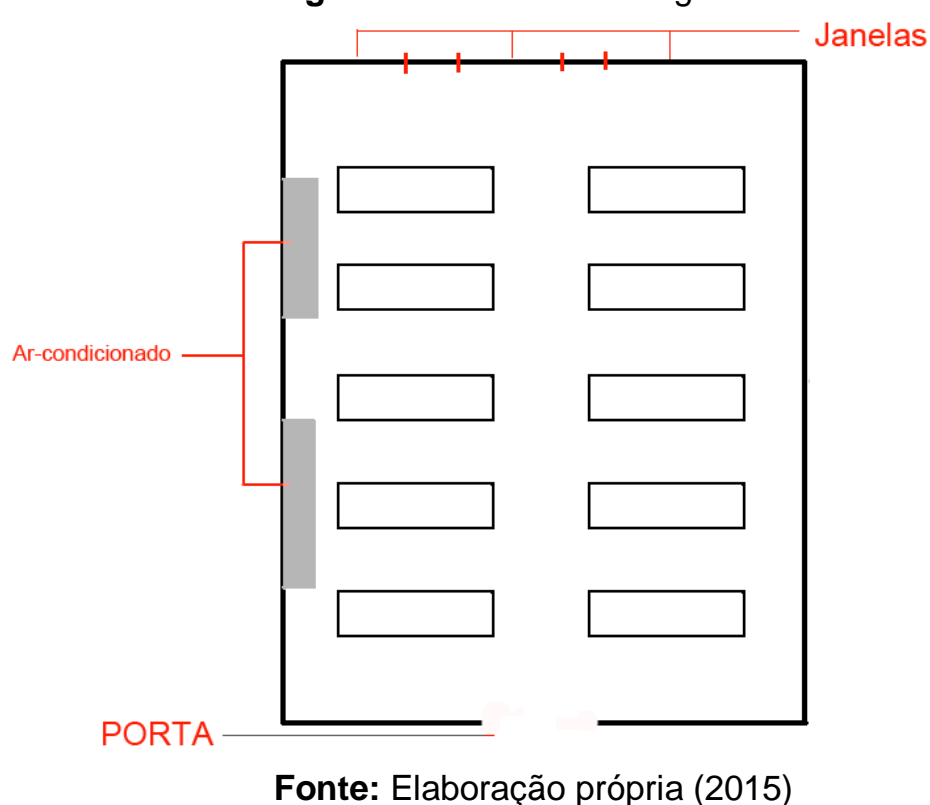


Os procedimentos utilizados nesse experimento foram os mesmos utilizados na região nordeste. Diante disso, as medições ocorreram em três dias, onde a temperatura do ar foi programada para $20^{\circ}, 24^{\circ}$ e $28^{\circ} \mathrm{C}$. Fizeram parte da amostra 30 alunos da área de exatas, onde os mesmos foram submetidos a uma avaliação subjetiva, bem como, foi feita uma avaliação objetiva similar a aplicada na região nordeste.

Para a medição dos parâmetros físicos foi utilizado uma estação microclimática localizada no centro do ambiente. Conforme procedimento padrão, após 30 minutos de aclimatação e estabilização iniciava-se o registro dos dados de minuto a minuto.

\section{RESULTADOS}

\subsection{Resultados instituição região nordeste}

\subsubsection{Percepção dos estudantes}

Apresenta-se a seguir os resultados das sensações térmicas das três turmas levando em consideração as variações da temperatura do ar.

$\mathrm{Na}$ figura 6 verifica-se para as três turmas que o voto mais frequente foi de confortável. Entretanto, para a turma 1 e turma 2 nota-se que o número de votos para levemente desconfortável foi próximo aos que indicaram estar em conforto.

$\mathrm{Na}$ tabela 1 observa-se que para as temperaturas do ar de $20^{\circ} \mathrm{C}$ e $24^{\circ} \mathrm{C}$ predominou o voto em confortável, onde esse percentual variou conforme a turma e o dia. A turma 1 teve nos dois dias 50\% e 53,85\%, respectivamente; a turma 2, $51,85 \%$ e 53,85\%; e a turma 3, 58\% para os dois dias.

Para a temperatura de $28^{\circ} \mathrm{C}$ predominou a sensação de desconforto (Turma 1, 42,30\%; Turma 2, 36\% e turma 3,31,58\%). Entretanto, existiu um percentual de $31,58 \%$ na turma 3 que indicou o estado de conforto. 
Figura 6- Gráfico das percepções térmicas das turmas 1, 2 e 3

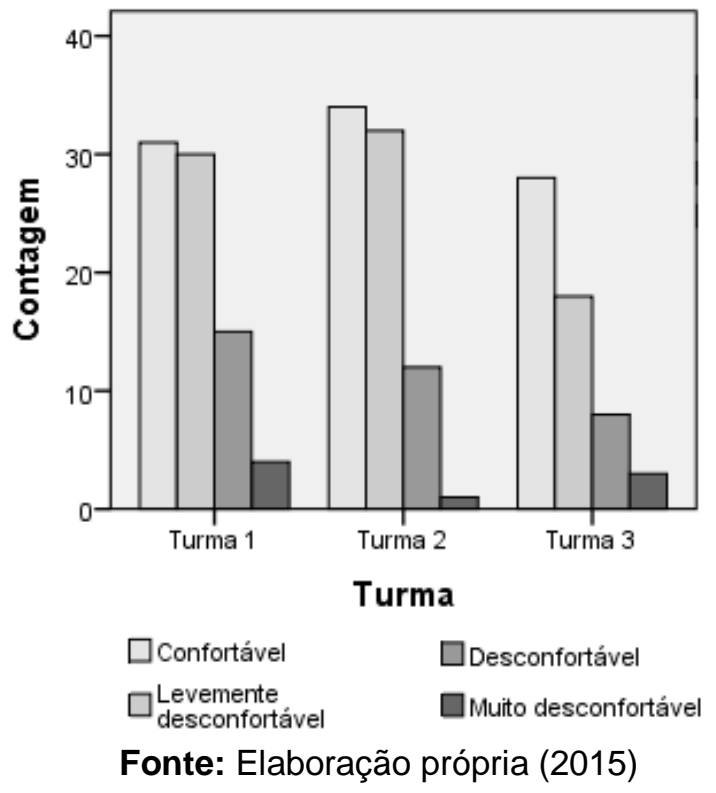

Tabela 1 - Estado indicado com mais frequência nos grupos

\begin{tabular}{|c|c|c|c|}
\cline { 2 - 4 } \multicolumn{1}{c|}{} & \multicolumn{3}{c|}{ Temperatura } \\
\hline 1 & Confortável & Confortável & $\begin{array}{c}\text { Levemente } \\
\text { desconfortável }\end{array}$ \\
\hline 2 & Confortável & Confortável & $\begin{array}{c}\text { Levemente } \\
\text { desconfortável } \\
\text { e }\end{array}$ \\
\hline 3 & Confortável & Confortável & $\begin{array}{c}\text { Confortável e } \\
\text { desconfortável }\end{array}$ \\
\hline & & & desconfortável \\
\hline
\end{tabular}

Fonte: Elaboração própria (2015)

Legenda:

$\square 31,58 \% \square 36 \% \square 42,30 \square 50 \% \square 51,85 \% \square 53,85 \% \square 58 \%$




\subsubsection{Percepção do conforto térmico para cada dia de análise}

Para o dia em que a temperatura proposta foi de $20^{\circ} \mathrm{C}$ observa-se na tabela 2 a predominância do estado confortável e, em segundo plano, levemente desconfortável.

Tabela 2 - Percepções térmicas a $20^{\circ} \mathrm{C}$

\begin{tabular}{|l|l|l|l|}
\hline & \multicolumn{3}{|c|}{ Turma } \\
\hline Estado & $\mathbf{1}$ & $\mathbf{2}$ & $\mathbf{3}$ \\
\hline Confortável & 14 & 14 & 11 \\
\hline Levemente & 10 & 11 & 7 \\
\hline desconfortável & 4 & 2 & 1 \\
\hline Desconfortável & 0 & 0 & 0 \\
\hline Muito desconfortável & 0 & & \\
\hline
\end{tabular}

Fonte: Elaboração própria (2015)

A tabela 3 indica uma preferência por uma temperatura do ar em torno de $24^{\circ}$ C. Assume-se isso pois o estado confortável foi o mais indicado para essas condições propostas, tendo em segundo plano, a indicação do voto levemente desconfortável.

Tabela 3 - Percepções térmicas a $24^{\circ} \mathrm{C}$

\begin{tabular}{|l|c|c|c|}
\hline \multicolumn{3}{|c|}{ Turma } \\
\hline Estado & $\mathbf{1}$ & $\mathbf{2}$ & $\mathbf{3}$ \\
\hline Confortável & 14 & 14 & 11 \\
\hline $\begin{array}{l}\text { Levemente } \\
\text { desconfortável }\end{array}$ & 9 & 11 & 7 \\
\hline Desconfortável & 3 & 1 & 1 \\
\hline Muito desconfortável & 0 & 0 & 0 \\
\hline
\end{tabular}

Fonte: Elaboração própria (2015) 
Para a temperatura de $28^{\circ} \mathrm{C}$ nota-se na tabela 4 que o voto que prevalece é o de levemente desconfortável e, em um segundo plano bem próximo, destaca-se o estado desconfortável.

Tabela 4 - Percepção térmica a $28^{\circ} \mathrm{C}$

Turma

\begin{tabular}{|l|c|c|c|}
\hline Estado & $\mathbf{1}$ & $\mathbf{2}$ & $\mathbf{3}$ \\
\hline Confortável & 3 & 6 & 6 \\
\hline Levemente desconfortável & 11 & 9 & 4 \\
\hline Desconfortável & 8 & 9 & 6 \\
\hline Muito desconfortável & 4 & 1 & 3 \\
\hline
\end{tabular}

Fonte: Elaboração própria (2015)

\subsubsection{Teste de hipótese}

Assumindo a hipótese nula de que as sensações térmicas são iguais utilizouse o teste Kruskal-wallis. A tabela 1 indica o "valor p" para a temperatura de $20^{\circ}$ igual a 0.36; para $24^{\circ} \mathrm{C}, 0.13$ e para $30^{\circ} \mathrm{C}, 0.14$. O "valor p" pode ser definido como sendo a probabilidade de erro ao rejeitar a hipótese proposta. Para probabilidades menores ou iguais a 5\% a hipótese nula é rejeitada.

Sendo assim, para esse estudo a hipótese nula não pode ser rejeitada e assume-se que não existiu diferença de percepção entre as turmas. Em função disso, torna-se possível considerar uma sensação similar para as três turmas dessa região.

Tabela 5 - Valor $p$

\begin{tabular}{|c|c|}
\hline TEMPERATURA & VALOR P \\
\hline $20^{\circ} \mathrm{C}$ & 0.3683 \\
\hline $24^{\circ} \mathrm{C}$ & 0.1354 \\
\hline $28^{\circ} \mathrm{C}$ & 0.1463 \\
\hline
\end{tabular}

Fonte: Elaboração própria (2015) 


\subsubsection{Estimativa de intervalo de conforto}

O resultado no teste anterior indicou que não existiu diferença de percepções entre os alunos das três turmas, ou seja, ocorreu a compatibilidade perceptiva. Diante dessa congruência estimou-se um intervalo de temperaturas de conforto sem distinção de turmas. Essa estimativa variou entre $22^{\circ} \mathrm{C}$ e $24^{\circ} \mathrm{C}$, com um nível de confiança de $95 \%$.

\subsubsection{Relação entre PMV e percepção de conforto}

A percepção de conforto foi classificada em confortável e desconfortável. Diante disso, foi feita uma análise para identificar a variação de cada categoria com relação ao PMV. A figura 7 mostra que a percepção dos estudantes para o estado confortável variou para um PMV próximo de -2 e próximo de -1. Essa constatação foi diferente do que era esperado pela escala proposta por Fanger (1970), onde o estado de conforto deveria variar para valores do PMV iguais ou próximos de zero. Para corroborar uma possível contradição com o estudo de Fanger, a sensação que prevaleceu para situações de desconforto também diferiu do valor esperado pela referida escala.

Diante disso, infere-se que se o PMV for adotado como método de avaliação e forem seguidas as designações normativas para atingir o conforto térmico, existe a possibilidade de que tais recomendações não sejam suficientes para que essa amostra atinja o estado de conforto térmico. Isso vai de encontro a um estudo realizado por ter Mors(2011), onde considera-se que o método PMV não é adequado para estudantes de uma escola primária na Holanda, e que o cumprimento das exigências normativas não é garantia de conforto térmico para os ocupantes. 
Figura 7 - Análise do PMV e percepção de conforto

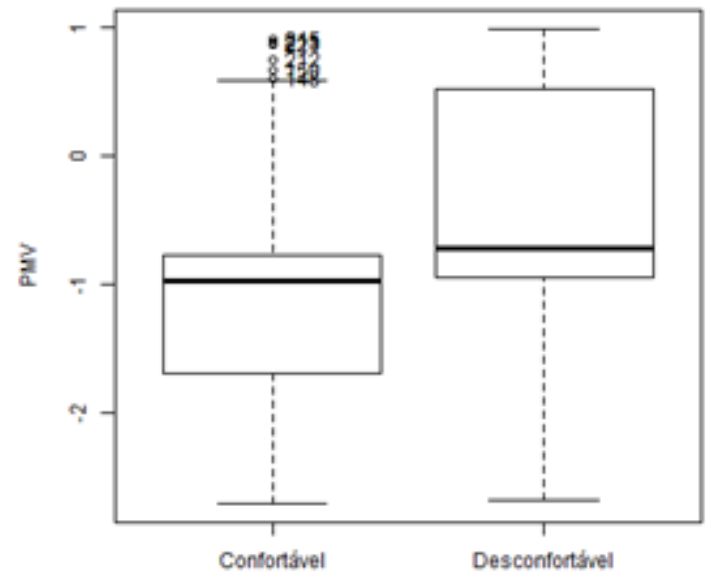

Fonte: Elaboração própria (2015)

\subsection{Instituição região Sudeste}

\subsubsection{Percepção do conforto térmico para cada dia de análise}

Para a temperatura de $20^{\circ}$ ficou perceptível que a maioria dos estudantes indicou o estado de neutralidade, ou seja, conforto térmico. A figura 8 mostra que $7 \%$ indicaram sentir um ambiente levemente frio; $13 \%$ indicaram o ambiente frio, e por fim, ainda existiram 13\% que achavam o ambiente levemente quente. Esses percentuais indicam uma possível adaptabilidade dos indivíduos a uma temperatura mais amena, adaptabilidade essa que surge das condições térmicas que esses estudantes são submetidos cotidianamente.

Figura 8 - Sensações térmicas a $20^{\circ} \mathrm{C}$

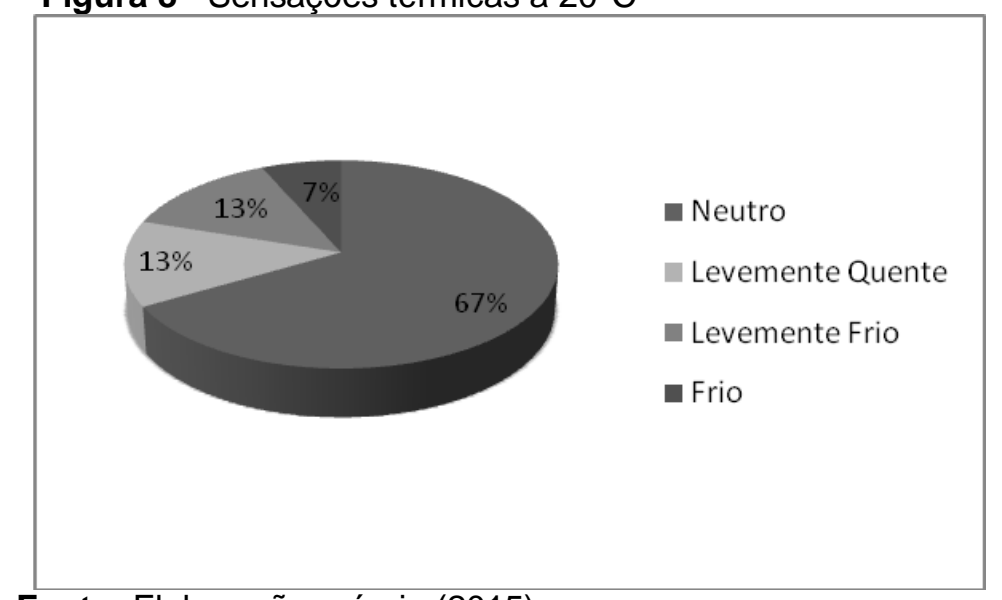

Fonte: Elaboração própria (2015) 
Para a temperatura de $24^{\circ} \mathrm{C}$ o estado que prevalece é o de neutralidade térmica. Entretanto, como mostra a figura 9 o percentual de indivíduos que indicaram sentir o ambiente levemente frio foi igual ao de estudantes que compreendiam o ambiente levemente quente (27\%). Logo, observa-se que as sensações térmicas dos ocupantes apresentaram leves discordâncias. Tais diferenças perceptivas já eram esperadas, entretanto, o percentual de $6 \%$ que indicou o ambiente frio foi 0 ponto que destoou da previsão inicial.

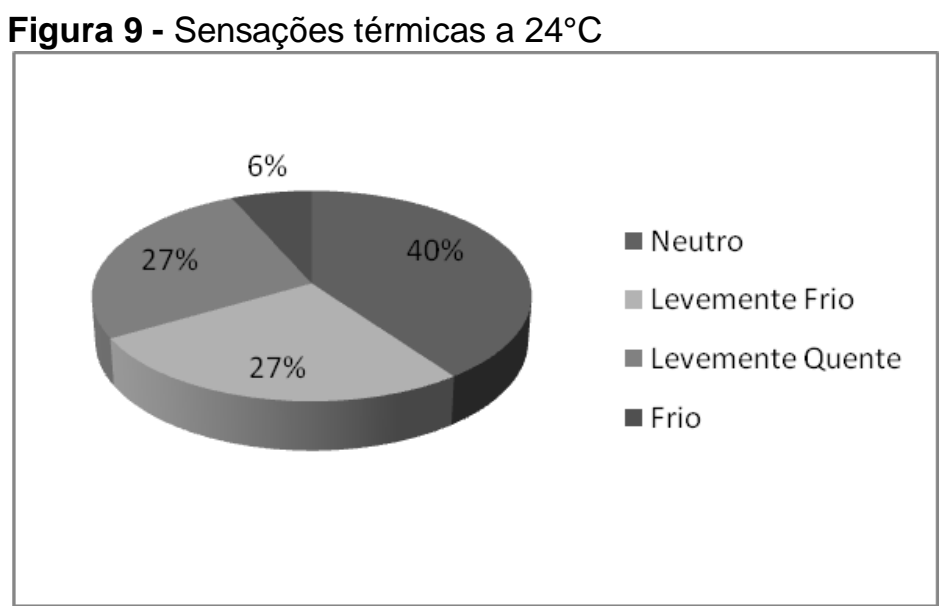

Fonte: Elaboração própria (2015)

Para o terceiro dia foi proposto uma temperatura elevada $\left(28^{\circ} \mathrm{C}\right)$, diante disso, a figura 10 mostra que prevaleceu a percepção de que o ambiente estava com condições térmicas acentuadas. Logo, o percentual de estudantes que sentiram o ambiente quente foi alto, 47\%; os indivíduos que indicaram o ambiente levemente quente representaram $27 \%$ da amostra estudada; e por fim, 13\% da amostra representaram o percentual de indivíduos que sentiram o ambiente quente e muito quente.

Diante da análise anterior desenvolveu-se a tabela 6 com a finalidade de possibilitar uma leitura objetiva da percepção térmica de acordo com as referidas temperaturas.

De acordo com essa tabela conclui-se que a neutralidade térmica foi o estado mais frequente. Entretanto, observa-se que o percentual desse estado em cada dia foi diminuindo. Para o dia em que a temperatura foi de $20^{\circ} \mathrm{C}$, o estado de neutralidade apresentou o maior percentual, com 67\%; para os dias seguintes esse percentual decaiu gradativamente. Para a temperatura de $24^{\circ} \mathrm{C}$ o percentual de 
estudantes com a sensação de neutralidade foi de $40 \%$ e para a temperatura de $28^{\circ} \mathrm{C}$ o percentual foi de $47 \%$.

Figura 10 - Sensações térmicas a $28^{\circ} \mathrm{C}$

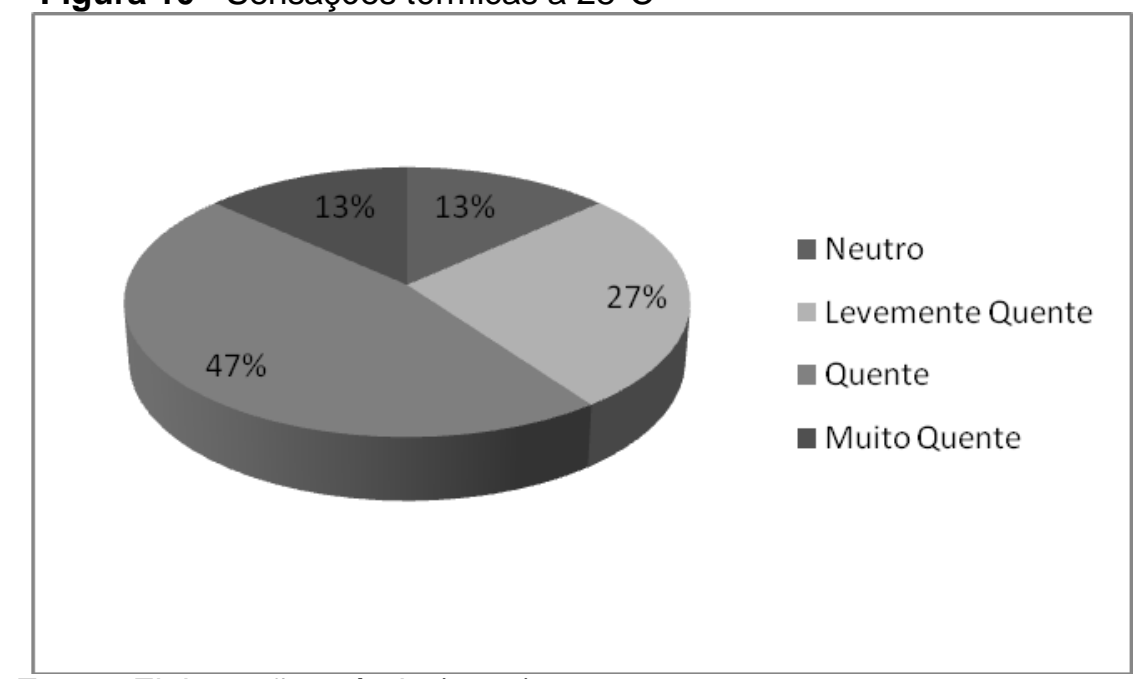

Fonte: Elaboração própria (2015)

Tabela 6 - Estados mais frequentes

\begin{tabular}{|c|c|}
\hline Temperatura & Estados mais frequentes \\
\hline $20^{\circ} \mathrm{C}$ & Neutro \\
\hline $24^{\circ} \mathrm{C}$ & Neutro \\
\hline $28^{\circ} \mathrm{C}$ & Neutro \\
\hline
\end{tabular}

Fonte: Elaboração própria (2015)

Legenda:

$67 \%$ neutro

$40 \%$ neutro

$47 \%$ neutro

\subsubsection{Intervalo de temperatura de conforto}

Após análise da percepção foi estimado um intervalo de temperaturas de conforto. Esse intervalo variou entre $23,14^{\circ}$ e $23,25^{\circ}$, com nível de confiança de 95\%. Ou seja, a partir do momento que for estimado uma temperatura do ar e ela estiver dentro do intervalo citado anteriormente, provavelmente a maioria dos estudantes ficariam em um estado de conforto térmico. 
O intervalo estimado é importante pois permite que o professor estipule a temperatura do ar adequada. Por sua vez, quando à temperatura do ar estiver dentro do intervalo calculado a maioria dos ocupantes entraram em uma zona de conforto, possibilitando assim, o não comprometimento das atividades em decorrência de questões térmicas.

\subsubsection{Relação entre PMV e percepção de conforto}

Para tal análise a percepção de conforto foi classificada em: confortável e desconfortável. Como mostra a figura 11 o estado de conforto variou para um PMV entre 0,3 e 0,6 aproximadamente. Vale ressaltar que existiram situações especificas onde os estudantes que indicaram a sensação de conforto apresentaram um PMV distante de zero. Por outro lado, a sensação de desconforto variou para um intervalo de PMV entre 0,5 e próximo de 1.

O estudo de Fanger (1970) indicou que o estado de conforto acontece para um PMV igual ou próximo de zero, e a sensação de desconforto existe para qualquer valor diferente disso. Sendo assim, interpreta-se para essa amostra que os estudos e a escala de Fanger (1970) aparentemente foram compatíveis.

Apesar dessa possível compatibilidade necessita-se fazer outras análises para comprovar ou não tal relação. É preponderante identificar se os resultados obtidos se enquadram perfeitamente nos resultados esperados pelo modelo, ou existe alguma variação. Essa variação indica a possível necessidade de adaptação do modelo a amostra em função da aclimatação com as condições térmicas da região. Diante disso, assume-se que para a amostra da região nordeste o estudo de Fanger necessitou ser adaptado em função da aclimatação dos estudantes com condições térmicas mais elevadas.

Quando se fala em uma possível adaptação do modelo de Fanger a amostra estudada, quer-se dizer que o resultado previsto pelo mesmo (Figura 12), PMV exatamente igual a zero indicando conforto e PMV diferente de zero indicando desconforto (desconforto por frio e desconforto por calor), pode não ser perfeitamente aplicável. Diz-se isso em função de uma possível variação na zona de conforto. Ou seja, se determinada amostra estiver aclimatada com condições 
ambientais mais frias, possivelmente a zona de conforto desses indivíduos compreenderam valores que o mesmo estipulou como sendo de desconforto por frio.

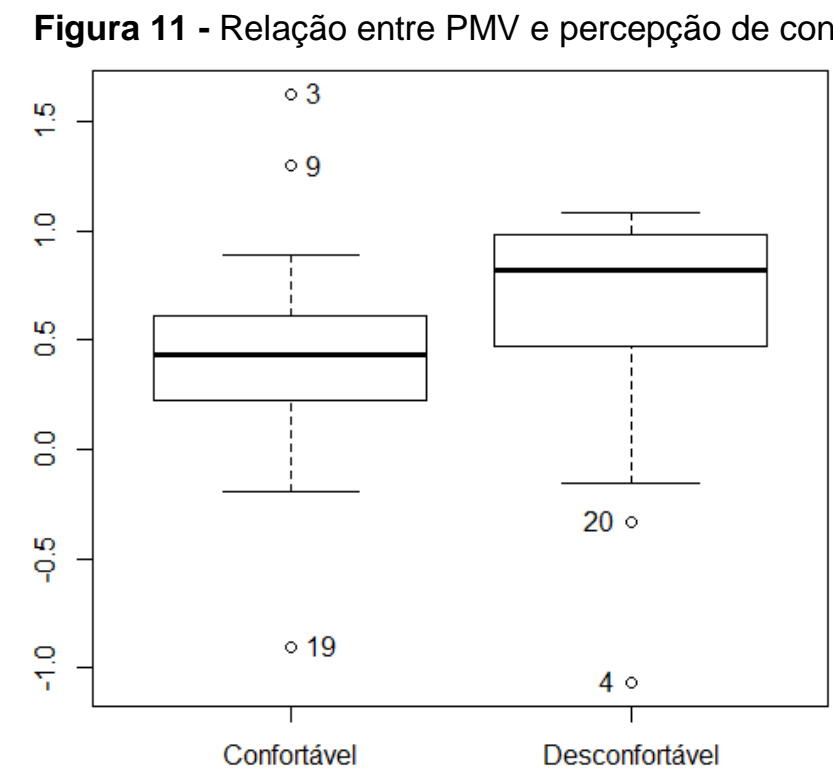

Fonte: Elaboração própria (2015)

Figura 12 - Escala de Fanger(1970)

\begin{tabular}{|c|c|c|c|c|c|c|c|}
\hline & -3 & -2 & -1 & 0 & 1 & 2 & 3 \\
\hline PMV & Muito frio & Frio & $\begin{array}{l}\text { Leve } \\
\text { sensação } \\
\text { de frio }\end{array}$ & Neutro & $\begin{array}{c}\text { Leve } \\
\text { sensação } \\
\text { de calor }\end{array}$ & Quente & $\begin{array}{l}\text { Muito } \\
\text { quente }\end{array}$ \\
\hline
\end{tabular}

Fonte: Fanger (1970)

\section{DISCUSSÃO}

Mediante as temperaturas propostas observou-se a diferença de percepção térmica entre os estudantes, o que reflete a subjetividade da percepção em um ambiente. Essa subjetividade é destacada por Teli et. al. (2014), que afirma que as fortes diferenças interpessoais decorrem das respectivas atividades realizadas pelo corpo de cada estudante. Essas atividades são preponderantes na determinação da percepção de conforto térmico.

Embora essa diferença tenha sido verificada, notou-se que entre as três turmas investigadas na região nordeste não existiram diferenças significativas na distribuição de frequência da percepção. Essa similaridade da percepção térmica 
pode ter ocorrido devido ao fato de pertencerem a uma mesma localidade, tendendo a serem compostas por pessoas que estão adaptadas a condições climáticas similares. Entretanto, observou-se que existiram diferenças perceptivas entre as amostras das duas regiões. Os estudantes da região sudeste apresentaram preferências por condições climáticas mais amenas e frias, resultado de uma possível aclimatação com as condições térmicas da região.

Os resultados comprovam a importância da aclimatação e adaptação térmica como variáveis decisivas no estudo do conforto térmico. Nesse sentido, Yang (2015) ressalta a importância da adaptação na determinação das percepções térmicas individuais e, consequentemente, dos grupos de indivíduos. Segundo o autor, a adaptação psicológica neutraliza a sensação térmica real das pessoas por meio da redução da sensibilidade térmica da pele, possibilitando a aclimatação.

Como não existiram diferenças significativas na distribuição da percepção entre as três turmas da região nordeste, considerou-se todos os indivíduos como pertencentes a um único grupo. Logo, através de intervalos livres de distribuição obteve-se uma estimativa da condição de conforto para esse grupo. $O$ intervalo de confiança obtido foi de $22^{\circ}$ a $24^{\circ} \mathrm{C}$, com nível de confiança de $95 \%$. Ou seja, quando a temperatura do ar estiver dentro do intervalo citado, a maioria dos estudantes possivelmente estará em uma zona de conforto. Já para a região sudeste a zona de conforto esteve para um intervalo entre $23,14^{\circ}$ e $23,25^{\circ}$. Logo, com essas estimativas torna-se possível controlar a temperatura e possibilitar o melhor desempenho das atividades nas salas de aula analisadas.

\section{CONCLUSÕES}

O presente artigo avaliou o conforto ambiental em duas salas de aula em regiões distintas, analisando a percepção térmica dos estudantes mediante a variação da temperatura do ar em 20,24 e $28^{\circ} \mathrm{C}$. Para os dois grupos estudados observou-se que a subjetividade da percepção térmica pode refletir nas diferenças de variação das atividades corporais. Essas distinções individuais repercutiram nas diferenças de distribuição das percepções e representaram uma variação aleatória natural entre os grupos. Por exemplo, no experimento realizado na região nordeste observou-se a preferência por temperaturas levemente elevadas. Essa constatação 
é justificada em virtude da aclimatação dos estudantes com o clima característico da região. Por outro lado, os estudantes do experimento da região sudeste mostraram uma afeição a temperaturas mais amenas em função da adaptabilidade com as condições térmicas da região.

Como a percepção térmica de um indivíduo é dotada de subjetividade, é muito difícil definir uma temperatura que mantenha todo um grupo numa condição de conforto. Porém, já que a adaptação psicológica é um componente determinante da percepção térmica, é esperado que em uma mesma localidade grupos de indivíduos tenham distribuição de frequência similar para a mesma temperatura. Neste sentido, é plausível a busca por estimativas de temperatura que tendem a manter uma condição de conforto para maior parte dos integrantes. Diante desse cenário, estimou-se uma faixa de conforto entre $22^{\circ} \mathrm{C}$ e $24^{\circ} \mathrm{C}$ para os indivíduos pesquisados na região nordeste; e $23,14^{\circ}$ e $23,25^{\circ}$ na região sudeste. Temperaturas nesse intervalo tendem a equilibrar a propensão dos indivíduos mais adaptados para temperaturas mais frias e a daqueles adaptados para temperaturas mais quentes, mantendo uma condição térmica que tende a ser de conforto para maior parte deles.

Buscar estimativas de temperatura do ar para condição de conforto térmico em sala de aulas é importante porque essa variável (dentre aquelas que determinam a sensação térmica) é controlada por sistemas de refrigeração. Esse controle eficiente ganha notoriedade a partir do momento que se reconhece que a condição de conforto térmico é relevante no processo de ensino aprendizagem.

\section{REFERÊNCIAS}

ALMEIDA, R. M. S. F.; DE FREITAS, V. P. Indoor environmental quality of classrooms in Southern European climate. Energy and Buildings. v. 81, p.127-140, 2014.

https://doi.org/10.1016/j.enbuild.2014.06.020

ASHRAE. Standard 55: thermal environmental conditions for human occupancy. Atlanta: ASHRAE, 2004.

BLATTEIS, C. M. Fisiologia e patofisiologia da regulação da temperatura. São Paulo: EDUSP, 1997.

COCHRAN, W. G. Sampling Techniques. 3. ed. New York: John Wiley \& Sons. 1997.

CONCEIÇÃO E. Z. E; LÚCIO M. M. J.R. Evaluation of thermal comfort conditions in a classroom equipped with radiant cooling systems and subjected to uniform convective 
environment. Applied Mathematical Modelling, v.35, p.1292-1305, 2011.

https://doi.org/10.1016/j.apm.2010.09.006

CORGNATI S. P.; ANSALDI R.; FILIPPI M. Thermal comfort in Italian classrooms under free running conditions during mid seasons: Assessment through objective and subjective approaches. Building and Environment. v. 44, p.785-792, 2009.

https://doi.org/10.1016/j.buildenv.2008.05.023

COUTINHO, A. S. Conforto térmico e insalubridade térmica em ambientes de trabalho. João Pessoa: Ed. Universitária, 2009.

FANGER, P. O. (1970). Thermal comfort. Copenhagen: Danish Technical Press.

HUSSIN M.; ISMAIL M.R.; AHMAD M.S. Subjective perception of thermal comfort study in air-conditioned university laboratories. Procedia - Social and Behavioral Sciences, v.91, p. 192- 200, 2013. https://doi.org/10.1016/j.sbspro.2013.08.417

INTERNATIONAL ORGANIZATION FOR STANDARD. ISO 7730: moderate thermal environments: determination of the PMV and PPD Indices and Specification of the conditions of Thermal Comfort. Geneva, 2005.

KATAFYGIOTOU M. C.; SERGHIDES D. K. Thermal comfort of a typical secondary school building in Cyprus. Sustainable Cities and Society. v.13, p. 303-312, 2014.

https://doi.org/10.1016/j.scs.2014.03.004

LAMBERTS, R.; XAVIER, A. A. P. Conforto térmico e stress térmico. Florianópolis: Universidade Federal de Santa Catarina, 2002.

MISHRA A. K.; RAMGOPAL M. Thermal comfort Field study in undergraduate laboratories An analysis of occupant perceptions. Building and Environment, v. 76, p. 62 - 72, 2014. https://doi.org/10.1016/j.buildenv.2014.03.005

TELI D.; JENTSCH M. F.; JAMES P. A.B. The role of a building's thermal properties on pupils' thermal comfort in junior school classrooms as determined in field studies. Building and Environment, v. 82, p.640-654, 2014. https://doi.org/10.1016/j.buildenv.2014.10.005

YANG, Y.; LI, B.;LIU, H.; TAN, M.; YAO, R. A study of adaptive thermal comfort in a wellcontrolled climate chamber. Applied Thermal Engineering. v. 76, p.283-291, fev. 2015. https://doi.org/10.1016/j.applthermaleng.2014.11.004

WANG, Z.;LI, A.;REN, J.;HE, Y.. Thermal adaptation and thermal environment in university classrooms and offices in Harbin. Energy and Buildings, v. 77, p. 192-196, 2014. https://doi.org/10.1016/j.enbuild.2014.03.054

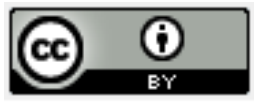

Artigo recebido em 04/08/2016 e aceito para publicação em 27/07/2017 DOI: http://dx.doi.org/10.14488/1676-1901.v17i3.2547 